\title{
Awkward Independents: What Are Third-Party Candidates Doing on Twitter?
}

\author{
Heather K. Evans, Sam Houston State University \\ Jessica Habib, Sam Houston State University \\ Danielle Litzen, Sam Houston State University \\ Bryan San Jose, Sam Houston State University \\ Ashlee Ziegenbein, Sam Houston State University
}

ABSTRACT Previous literature on partisan campaign behavior shows that third-party candidates do not have the same presence online as major-party candidates, and these differences have been linked regularly to campaign finance. Twitter, however, has changed the online campaigning game. Because Twitter essentially is free, third-party candidates can even the playing field with major-party candidates who have more financial resources. The question asked in this article is whether this is actually the case. Evans, Cordova, and Sipole (2014) showed that in 2012, third-party candidates were less likely to have accounts on Twitter; however, those who had accounts tweeted more often than major party candidates. This article updates those findings to consider the behavior of third-party candidates during the 2014 and 2016 congressional races. Using a dataset of all candidates for both the US House and the US Senate, we show that the gap has begun to close between major- and minor-party candidates on Twitter. Third-party candidates, however, continue to have a different way of communicating with their followers on Twitter when compared to Democrats and Republicans.

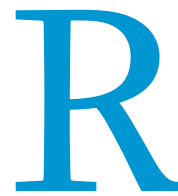

egarding campaigning in the twenty-first century, social media (especially Twitter) cannot be ignored. At the beginning of $2016,44 \%$ of US adults reported that they had learned about the presidential election in the last week from social media, more than from any other media source (Gottfried et al. 2016). In August 2017, the percentage increased: $67 \%$ of Americans reported that they get some of their news on social media (Shearer and Gottfried 2017).

Heather K. Evans is associate professor of political science at Sam Houston State University. She can be reached at hkeooz@shsu.edu.

Jessica Habib is an undergraduate student at Sam Houston State University. She can be reached atjxho84@shsu.edu.

Danielle Litzen is an undergraduate student at Sam Houston State University. She can be reached atdmloz2@shsu.edu.

Bryan San Jose is an undergraduate student at Sam Houston State University. He can be reached at btso18@shsu.edu.

Ashlee Ziegenbein is an undergraduate student at Sam Houston State University. She can be reached at anzoo8@shsu.edu.
On Twitter, specifically, $74 \%$ of users report getting news from the site, an increase of 15 percentage points from the previous year (Shearer and Gottfried 2017).

While the percentage of adults turning to Twitter and other social networks for news has increased in recent years, there also has been growth in the adoption of social media by politicians. In 2011, only $44 \%$ of US senators were on Twitter; however, by 2013 , 100\% had adopted an account (Toor 2013). Since then, there has been an explosion of research in the area of Twitter and elections (Jungherr 2016).

There was hope in the beginning that the growth of social media for news would level the playing field for political candidates who lack the resources of incumbents. Twitter essentially is free (i.e., there is no membership fee or cost to use it) and a user can tweet as often as the mood inspires. Many hoped that especially third-party candidates would benefit from the platform because even those without financial resources can create and use these accounts (Gibson and McCallister 2009; Price 2012). 
Work in this area, however, suggests that there is a relationship between campaign funding and using Twitter (Ammann 2010; Evans and Sipole 2017). Although tweeting is free, it takes time to draft and send tweets; therefore, those who have the monetary resources to hire staff to tend to their Twitter accounts are more likely to tweet (Ammann 2010; Evans, Cordova, and Sipole 2014). Using social media also exacerbates the gaps in monetary resources that already exist between major- and minor-party candidates (Hong 2013).

Early work on third-party candidates and their propensity to tweet, however, suggests that this might not always hold true. Evans, Cordova, and Sipole (2014) showed that although thirdparty candidates were less likely to have accounts during the 2012 US House elections, if they did have an account, they were more likely than their major-party colleagues to use it. Even when campaign spending was controlled, third-party candidates were still more active on Twitter than major-party candidates (Evans and Sipole 2017).

There is limited scholarship that examines the way that thirdparty candidates use Twitter, and the work that exists examines only a single election or a single chamber. To see whether the playing field is evening out on Twitter between third-party and major-party candidates, this article uses data collected across three elections and within two chambers. The following discussion reexamines the original 2012 data from Evans, Cordova, and Sipole (2014) and adds all of the tweets sent by all candidates for both the US House and the US Senate in 2014 and 2016. Although we demonstrate that there is still an adoption gap between thirdparty and major-party candidates, the former continue to have a different way of communicating with their followers on Twitter. Third-party candidates tweet more personal and less professional statements than major-party candidates.
Furthermore, it is impossible to discuss elections these days and not mention social media. Various authors have found that what candidates do on social media can affect their likelihood of winning and that Twitter can be analyzed to predict election outcomes (Tumasajan et al. 2011). Scholars found that citizens are greatly affected by what they see on Twitter, and politicians can mobilize followers and increase their fundraising by sending tweets (Hong 2013; Park 2013).

Since tweeting can matter for political engagement and is helpful for out-party candidates, are third-party candidates using this platform in the United States? There are limited studies that examine third parties and Twitter behavior (Christensen 2013; Conway, Kenski, and Wang 2013; Evans 2017; Evans, Cordova, and Sipole 2014; Evans and Sipole 2017; LaMarre and SuzukiLambrecht 2013). Some of the existing work explores the way that presidential candidates tweet (Christensen 2013; Conway, Kenski, and Wang 2013; Jackson 2016). However, given the limited number of cases in those studies, there is little to extrapolate regarding the way that third-party candidates tweet in general. For congressional elections, in their study involving the 2010 US House election, LaMarre and Suzuki-Lambrecht (2013) provided an initial look at whether third-party candidates were as likely to adopt a Twitter account. They found that third-party candidates were significantly less likely to have a Twitter account (i.e., 20.3\% compared to $66 \%$ of Democrats and $79 \%$ of Republicans).

Haber (2011) also explored the Twitter behavior of candidates for the US Senate in the 2010 election. Although Haber examined only the Twitter behavior of viable third-party candidates, he found that Republicans and third-party candidates tweeted more often than Democrats in 2010.

Evans, Cordova, and Sipole (2014) examined both the adoption and use of Twitter for all candidates running for the 2012 US

\section{To see whether the playing field is evening out on Twitter between third-party and major-party candidates, this article uses data collected across three elections and within two chambers.}

\section{LITERATURE REVIEW}

Regarding the way that candidates campaign, many scholars have argued that the party that controls the majority can provoke those not in the majority to campaign in innovative ways, including using new media (Appleton and Ward 1997; Lowi 1963; Tarrow 1998). Twitter offers many advantages to the out party. First, Twitter essentially is free. For candidates who lack the monetary resources to hire a professional staff, this is a benefit. Second, Twitter provides an outlet that bypasses the traditional media gatekeepers. If something happens in the world, users can go to Twitter to immediately respond or state their opinions on the matter instead of waiting to be invited on political-news programs. Because we now exist in the world of the shrinking sound bite and third-party candidates suffer in terms of their coverage in traditional news programming, tweets are "becoming the new 'sound bite,' allowing candidates to control more of the coverage of their public images and their campaigns" (Johnson 2012, 55). Twitter provides unlimited space for users to express their thoughts. Some authors have found that social media generally levels the playing field in terms of candidate mentions (Metzgar and Maruggi 2009).
House elections. Content analyzing every tweet sent from each candidate, they showed that whereas third-party candidates were again less likely to have accounts, those who had accounts used them more aggressively. Third-party candidates tweeted more often and sent more personal (i.e., non-campaign) tweets than major-party candidates. Third-party candidates also were more likely to send tweets about political issues than major-party candidates. These results were confirmed by a second study by Evans and Sipole (2017). Even after controlling for campaign finance, third-party candidates sent more issue-specific and personal tweets than major-party candidates.

Further work by Evans regarding the 2014 US House elections showed that third-party candidates were less likely to send tweets about civic engagement. Third-party candidates sent fewer tweets about voting, registration, volunteering, and joining a political cause (Evans 2017). These findings hold as well for Senate candidates in 2014 .

Reviewing other online media, there is not much work involving third parties. What exists suggests that there also is a gap between third-party and major-party candidates on websites, but the gap may be shrinking. Gulati and Williams (2007) showed that there 
was a significant increase in website presence of third-party US Senate candidates between 2004 and 2006. There was, however, a decent gap that still existed between major-party and third-party candidates in the US House elections. For both chambers, majorparty candidates were more likely to include a biography and news on their websites; however, as they described, this might be because third-party candidates were less likely to hold events. Third-party candidates were as likely to express their issue positions on their websites, but major-party candidates were twice as likely to post audio and video. Similar to the Evans and Sipole (2017) findings described previously, in the US Senate elections, major-party candidates also were more likely to have online volunteer sign-ups and to provide information on where and how to vote.

To summarize, there is little work on which to draw any formidable conclusions regarding how third-party candidates use Twitter. It seems that third-party candidates are less likely to have an online presence (i.e., whether a website or a Twitter account), and they spend their time discussing different topics than major-party candidates, perhaps to the detriment of their campaign. The following discussion explores how third-party candidates have used Twitter during the past three elections. tweeted something about an issue but did not take a side on it (e.g., "Here's an article about the Dream Act"), the tweet was coded as a policy statement. If a candidate took a side on the issue (e.g., "I fully support the implementation of the Dream Act"), the tweet was coded as position taking. ${ }^{4}$

- Attack: These tweets were those in which candidates made unflattering statements about their opponents.

- Attack Other: These tweets were those featuring negative statements about the Democratic Party, Republican Party, government, current president, or other group (e.g., the media).

- Personal: These were the tweets that did not fit in any of the previous categories-for example, those in which a candidate wished someone a happy birthday.

The intercoder reliability was calculated for each sample across the three periods. The coders in each sample achieved a minimum $90 \%$ agreement.

In the following results, we divided our sample by party identification. All independent and third-party candidates were grouped together, whereas Republicans and Democrats were analyzed separately. 5 Party identification was gathered from Ballotpedia.

\section{It seems that third-party candidates are less likely to have an online presence (i.e., whether a website or a Twitter account), and they spend their time discussing different topics than major-party candidates, perhaps to the detriment of their campaign.}

\section{METHODS}

To determine the effect of partisanship on the way candidates use Twitter, we collected and hand-coded tweets sent from every candidate running for the US House in 2012, 2014, and 2016 and for the US Senate in 2014 and 2016. In all, this resulted in a dataset of 3,456 candidates across those three years for the US House and 309 candidates for the US Senate. ${ }^{1}$ The first step was to locate the Twitter accounts for all candidates running for the US House and US Senate. As in previous research, we then hand-collected or downloaded the final two months of their Twitter history before each election (Evans and Clark 2016; Evans, Cordova, and Sipole 2014; Gainous and Wagner 2014). This allowed us to examine all campaigns after the end of the primary season, producing a dataset of 230,907 total tweets for the US House and 54,604 total tweets for the US Senate across those three elections. ${ }^{2}$

After we collected the tweets for these years, we then handcoded them for content. Following Evans, Cordova, and Sipole (2014), we coded the tweets using the following categories3:

- Campaign: These were tweets in which candidates talked about where they had been during the campaign and with whom they had been meeting. These tweets also included those in which candidates linked videos that their campaign had made or linked to their websites for information about their candidacy.

- Media: These tweets were those in which candidates encouraged followers to either watch a program they would be on or linked a newspaper article written about them.

- Position Taking/Policy Statement (Issues): These tweets were meant to bring awareness to a public-policy area. If a candidate
All candidates were examined for their adoption of a Twitter account, and only those with accounts were compared for their use of the social-network site. In 2012, only original tweets were analyzed. In 2014, original and retweets were included. In 2016, only original tweets were included.

Given the similarity of findings for both the US House and the US Senate during these election years, only the former results are presented. US Senate results are available in the online appendix and the overall findings are discussed in the conclusion.

\section{RESULTS: 2012}

In 2012, third-party candidates in the US House were significantly less likely to have Twitter accounts. Only $25.2 \%$ of thirdparty candidates had accounts, whereas $84.8 \%$ of Republicans and $81.1 \%$ of Democrats had accounts.

In terms of use, Republicans and Democrats acted similarly in their use of the platform (figure 1). Democrats tweeted, on average, 84 times, whereas Republicans tweeted 81 times during the final two months of the campaign. The content of their tweets also was similar: both used campaign tweets, media tweets, personal tweets, and issue-specific tweets at an equal rate. Democrats were slightly more likely to use attack and user-interaction tweets, whereas Republicans were more likely to use attack Democrat tweets. However, the differences were not statistically significant.

Third-party candidates, conversely, were using Twitter in a completely different way. Although most third-party candidates did not have accounts, those who used the social-network site were more aggressive. They tweeted, on average, 136 times during the final two months of the campaign. However, that average 
Figure 1

2012 US House Twitter Style

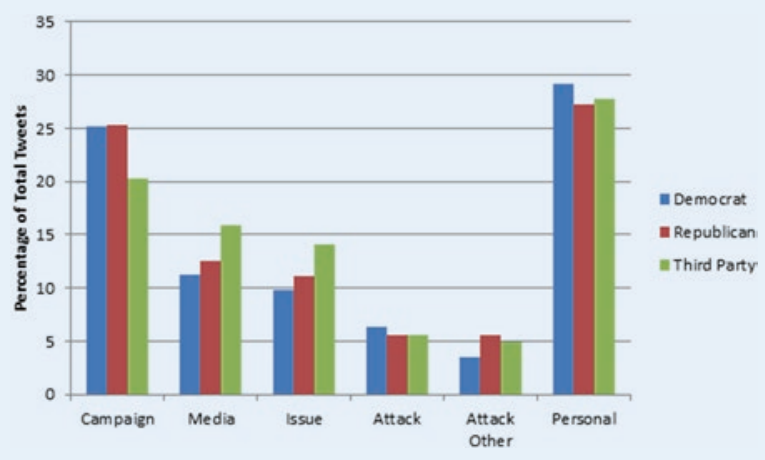

includes one third-party candidate (i.e., Steve Carlson, Minnesota District 4) who tweeted significantly more than the other candidates (i.e., 1,133 tweets). When Carlson is omitted from the analysis, third-party candidates sent, on average, 121 tweets-which is still significantly more than the Republican and Democratic candidates' average. ${ }^{6}$ Third-party candidates also were more likely to discuss their appearances in the media and bring up issues tweets sent during the final two months of the race was 57.45 . When we examined adoption and tweeting by partisanship, we found-as in previous years- that third-party candidates were less likely to have accounts. Of the 258 third-party candidates running in the 2016 US House races, only 63 had accounts (24.4\%) compared to $70.8 \%$ of Republican and $79 \%$ of Democratic candidates. The percentage of third-party candidates that had accounts is similar to the 2012 findings.

Third-party candidates also sent fewer tweets than majorparty candidates in 2016 but not significantly fewer. On average, third-party candidates sent 49.8 tweets during the final two months of the election, whereas Republicans sent 54 and Democrats sent 61.8.

The content of the tweets from major-party and third-party candidates was different in ways similar to 2012 and 2014. As in both earlier elections, third-party candidates were less likely to tweet about their campaigns than major-party candidates. They also sent significantly more personal tweets. ${ }^{10}$ More than $60 \%$ of third-party candidate tweets were unrelated to their campaigns, whereas only $28 \%$ of Democratic and $37 \%$ of Republican candidate tweets followed suit. Democrats also sent more attack tweets than Republicans and third-party candidates (figure 3). Third-party candidates sent no media tweets during the election but sent proportionately more policy-statement tweets than the major-party candidates, which also is similar to the earlier elections.

\section{More than 6o\% of third-party candidate tweets were unrelated to their campaigns, whereas only $28 \%$ of Democratic and $37 \%$ of Republican candidate tweets followed suit.}

in their tweets; they were less likely to send traditional "campaign"related tweets.7

\section{FINDINGS: 2014}

In the US House in 2014, there were 1,125 candidates, 306 of whom were third-party candidates (27.2\%). Third-party candidates in 2014 also were less likely to have a Twitter account. Only 121 of those candidates were tweeting during the race (39.5\%), which is a significant increase from the previous year $(25.2 \%)$. For comparison, $88 \%$ of Democrats and $89 \%$ of Republicans had Twitter accounts.

In the final two months of the 2014 US House races, the number of tweets sent from these respective parties was about equal, with both Republicans and third-party candidates sending approximately 135 tweets each, on average, and Democrats sending $148 .{ }^{8}$ When we examined the content of their tweets, we found that third-party candidates were tweeting similarly to major-party candidates, except in one area. Minor-party candidates were significantly less likely to use campaign tweets than major-party candidates (figure 2). .9 Although they sent more policystatement, position-taking, and personal tweets than major-party candidates, those differences were not significant. However, they seemed to be more focused on issues on Twitter than major-party candidates.

\section{FINDINGS: 2016}

During the 2016 US House races, there were 1,212 candidates but only 774 of them used Twitter. The average number of original

\section{DISCUSSION AND CONCLUSION}

Our results indicate that third-party candidates do not use Twitter similarly to major-party candidates. Third-party candidates are significantly less likely to have Twitter accounts. Although there has been a minor increase in Twitter adoption since the early results of LaMarre and Suzuki-Lambrecht (2013), there still exists a large gap between third parties and major parties in terms of their Twitter adoption, which may affect election results.

Third-party candidates sent more tweets than major-party candidates during the 2012 US House races but had a number

\section{Figure 2}

\section{US House Twitter Style}

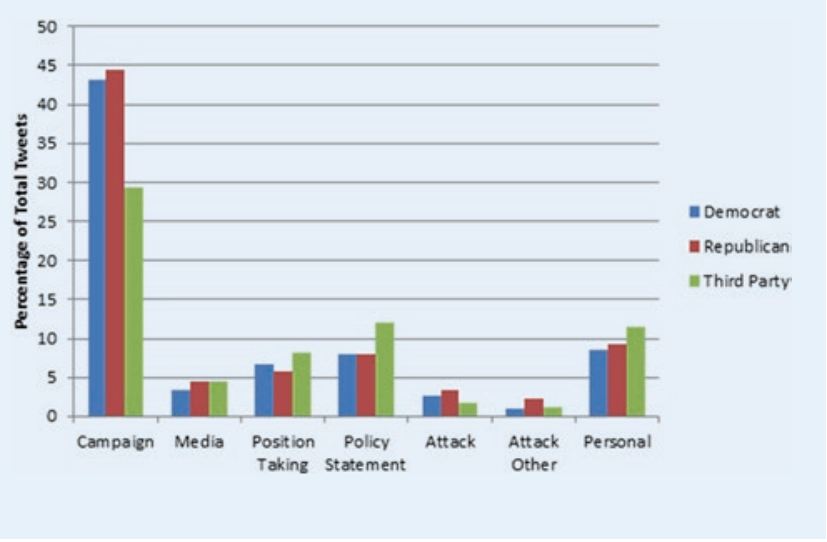


Figure 3

2016 US House Twitter Style

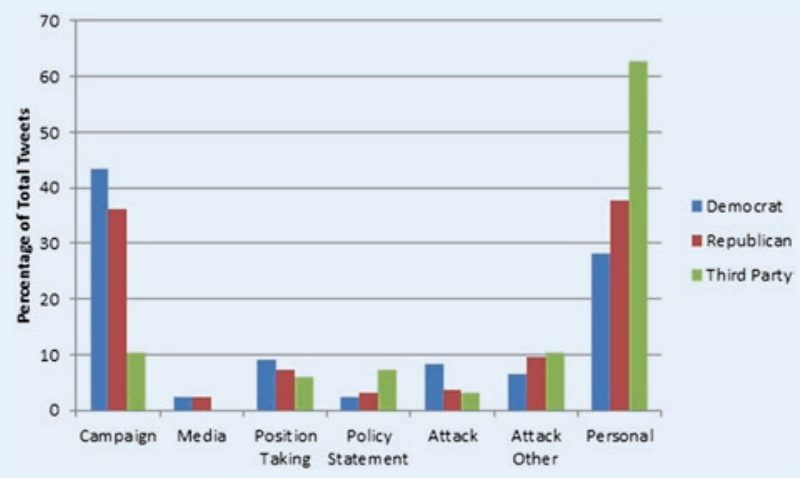

of tweets comparable to major-party candidates in the 2014 and 2016 races. In the US Senate races, third-party candidates sent significantly fewer tweets than major-party candidates across both years (see the online appendix). The average number of tweets sent by major-party candidates across these years did not change significantly.

When we reviewed the content of the tweets, across all three years, third-party candidates tweeted more about issues than major-party candidates. As the realignment literature suggests, during times of third-party strength, particular issues are not addressed adequately by the two major parties (Rosenstone, Behr, and Lazarus 1984). This may explain why third-party candidates are spending more time discussing issues. Because they obviously feel left out of politics, these candidates spend more time talking about issues for which they care deeply. During the 2014 election, for instance, we found that third-party candidates who were excluded from the debates in their districts and states were likely to live-tweet their responses to questions asked at the debates-which many times resulted in tweets about issues. The major-party candidates, conversely, were not sending those types of tweets because their answers were being broadcast on traditional media.

Third-party candidates also were more likely to tweet about personal issues and less likely to send traditional "campaign" tweets. Similar to the work by Gulati and Williams (2007) involving campaign websites, we believe that these differences may be attributed to the sheer number of campaign events that thirdparty candidates have relative to major-party candidates. Perhaps they tweet less about their campaign because there are not as many events to discuss and campaign ads to share.

By not using Twitter, third-party candidates are missing approximately one fourth of US adults who are using Twitter (Greenwood, Perrin, and Duggan 2016), especially younger adults, who are already more likely to adopt positions that are in line with third-party candidates (Hindman and Tamas 2016). Research shows that third-party candidates get little traction in traditional media coverage (Hindman and Tamas 2016; Morse 2016); therefore, using Twitter would allow them to bypass the traditional media gatekeepers. Other research found that winners of elections send more messages and spend more time on mobilization of their followers on Twitter (Evans, Ovalle, and Green 2016). Therefore, third-party candidates should reevaluate how they spend their time on Twitter.
Furthermore, Hong (2013) showed that social media use results in increased donations from outside donors. Given how limited campaign funding is for third-party candidates, they should think more seriously about adopting and using Twitter. Hong's (2013) research also found that politicians who have more extreme ideologies benefit the most from adopting social media, which means that third-party candidates should benefit the most from using Twitter. For all of these reasons, third-party candidates should consider using Twitter in their campaigns. Instead of discussing personal issues on Twitter, third-party candidates should explore ways to increase their campaign funding using this social network.

\section{SUPPLEMENTARY MATERIAL}

To view supplementary material for this article, please visit https://doi.org/10.1017/S1049096518001087

\section{NOTES}

1. There were 1,119 candidates in the 2012 US House dataset. One candidate was excluded from the analysis: Paul Ryan. There were 140 candidates in the 2014 US Senate dataset. The 2014 US House dataset contained 1,125 candidates. There were 1,212 candidates running for US House seats in 2016. In 2016, 169 candidates ran for US Senate seats.

2. There were 67,119 tweets in the 2012 US House dataset. There were 36,796 tweets sent during the 2014 US Senate race. There were 119,319 tweets in the 2014 US House dataset (including retweets). There were 44,469 tweets in the 2016 US House dataset and 17,808 tweets in the US Senate races.

3. For examples, see the online appendix.

4. In 2012, we decided against coding for specific issues or splitting our coding on issues by whether the candidate actually took a position on the topic. In the following analysis, we use only one category in 2012 for issues.

5. Future work should examine the differences between different types of thirdparty candidates (i.e., independents versus other minor third-party candidates)

6. Difference of means t-test, $\mathrm{p} \leq 0.05$.

7. Difference of means t-test, $\mathrm{p} \leq 0.05$.

8. This number includes retweets for 2014 .

9. Difference of means t-test, $\mathrm{p} \leq \mathrm{0.01}$.

10. Difference of means t-test, $\mathrm{p} \leq 0.01$. $<$ end endnotes $>$

\section{REFERENCES}

Ammann, Sky L. 2010. "A Political Campaign Message in 140 Characters or Less: The Use of Twitter by US Senate Candidates in 2010." Available at Social Science Research Network: http://ssrn.com/abstract=1725477.

Appleton, Andrew M., and Daniel S. Ward. 1997. "Party Response to Environmental Change." Party Politics 3 (3): 341-62.

Christensen, Christian. 2013. "Wave-Riding and Hashtag-Jumping: Twitter, Minority 'Third Parties' and the 2012 US Elections." Information, Communication \& Society 16 (5): 646-66.

Conway, Bethany Anne, Kate Kenski, and Di Wang. 2013. “Twitter Use by Presidential Primary Candidates During the 2012 Campaign." American Behavioral Scientist 57 (11): 1596-610.

Evans, Heather K. 2017. "Communication with Constituents in 140 Characters: How Members of Congress Used Twitter to Get Out the Vote in 2014." In Twitter and Elections Around the World: Campaigning in 140 Characters or Less. Ed. Richard Davis, Christina Holtz-Bacha, and R. Marion Just, 75-89. Abingdon-onThames, England: Routledge.

Evans, Heather K., and Jennifer Hayes Clark. 2016. “"'You Tweet Like a Girl!”: How Female Candidates Campaign on Twitter." American Politics Research 44 (2): 326-352.

Evans, Heather K., Victoria Cordova, and Savannah Sipole. 2014. "Twitter Style: An Analysis of How House Candidates Used Twitter in the 2012 Campaigns." PS: Political Science and Politics 47 (2): 454-62.

Evans, Heather K., Joycelyn Ovalle, and Stephen Green. 2016. "Rockin' Robins: Do Congresswomen Rule the Roost of the Twittersphere?" Journal of the Association for Information, Science and Technology 67 (2): 268-75.

Evans, Heather K., and Savannah Sipole. 2017. "From Home Style to Twitter-Style: How Personal, District, and Campaign Characteristics Affect House Candidates' Twitter-Style." In Social Media and Politics: A New Way to Participate in 
the Political Process. Ed. Glenn W. Richardson, Jr., 71-88. Santa Barbara, CA: Praeger Publishing.

Gainous, Jason and Kevin M. Wagner. 2014 Tweeting to Power: The Social Media Revolution in American Politics. New York: Oxford University Press.

Gibson, Rachel K., and Ian McAllister. 2009. "Crossing the Web 2.o Frontier? Candidates and Campaigns Online in the Australian Federal Election of 2007." Paper presented at the European Consortium for Political Research General Conference, Potsdam, Germany.

Gottfried, Jeffrey, Michael Barthel, Elisa Shearer, and Amy Mitchell. 2016. "The 2016 Presidential Campaign: A News Event That's Hard to Miss.” Washington, DC: Pew Research Center. Available at www.journalism.org/2016/o2/o4/the 2016-presidential-campaign-a-news-event-thats-hard-to-miss.

Greenwood, Shannon, Andrew Perrin, and Maeve Duggan. 2016. "Social Media Update 2016." Washington, DC: Pew Research Center. Available at www.pewinternet. org/2016/11/11/social-media-update-2016.

Gulati, Girish J., and Christine B. Williams. 2007. "Closing the Gap, Raising the Bar: Candidate Website Communication in the 2006 Campaigns for Congress." Social Science Computer Review 25 (4): 443-65.

Haber, Steven. 2011. "The 2010 US Senate Elections in 140 Characters or Less: An Analysis of How Candidates Use Twitter as a Campaign Tool." Available at http://aladinrc.wrlc.org/bitstream/handle/1961/10028/Haber,\%2oSteven\%20-\%20 Spring\%20\%2711.pdf? sequence $=1$.

Hindman, Matthew Dean, and Bernard Tamas. 2016. "The US Has More ThirdParty Candidates Than It's Seen in a Century. Why?" The Monkey Cage,

Washington Post. Available at www.washingtonpost.com/news/monkey-cage/ $\mathrm{wp} / 2016 / 08 / 31 /$ the-u-s-has-more-third-party-candidates-than-its-seen-in-acentury-why/?utm_term=.c88998f14767.

Hong, Sounman. 2013. "Who Benefits from Twitter? Social Media and Politica Competition in the US House of Representatives." Government Information Quarterly 30 (4): 464-72.

Jackson, Sam. 2016. "Follow the Leaders? Jill Stein and Gary Johnson's Twitter and Facebook Activity." New York: Tow Center for Digital Journalism. Available at https://towcenter.org/follow-the-leaders-jill-stein-and-gary-johnsons-twitterand-facebook-activity.
Johnson, Janet. 2012. "Twitter Bites and Romney: Examining the Rhetorical Situation of the 2012 Presidential Election in 140 Characters." Journal of Contemporary Rhetoric 2 (3/4): 54-64.

Jungherr, Andreas. 2016. "Twitter Use in Election Campaigns: A Systematic Literature Review." Journal of Information, Technology, and Politics 13 (1): 72-91.

LaMarre, Heather L., and Yoshikazu Suzuki-Lambrecht. 2013. "Tweeting Democracy? Examining Twitter as an Online Public Relations Strategy for Congressional Campaigns." Public Relations Review 39 (4): 360-68.

Lowi, Theodore. 1963. "Toward Functionalism in Political Science: The Case of Innovation in Party Systems." American Political Science Review 57 (3): 570-83.

Metzgar, Emily, and Albert Maruggi. 2009. "Social Media and the 2008 US Presidential Election." Journal of New Communications Research 4 (1): 141-65.

Morse, Brandon. 2016. "3rd Parties Getting Less Than 1\% of Media Attention, Despite Mainstream Parties Unpopularity." RedState. Available at www.redstate. com/brandon_morse/2016/o9/o7/3rd-parties-getting-less-1-media-attentiondespite-mainstream-parties-unpopularity.

Park, Chang Sup. 2013. "Does Twitter Motivate Involvement in Politics? Tweeting, Opinion Leadership, and Political Engagement." Computers in Human Behavior 29 (4): 1641-8.

Price, Tom. 2012. "Social Media and Politics: Do Facebook and Twitter Influence Voters?" CQ Researcher 22 (36).

Rosenstone, Steven J., Roy L. Behr, and Edward H. Lazarus. 1984. Third Parties in America: Citizen Response to Major-Party Failure. Princeton, NJ: Princeton University Press.

Shearer, Elisa, and Jeffrey Gottfried. 2017. "News Use Across Social Media Platforms 2017." Washington, DC: Pew Research Center. Available at www.journalism. org/2017/09/07/news-use-across-social-media-platforms-2017.

Tarrow, Sidney. 1998. Power in Movement. New York: Cambridge University Press.

Toor, Amar. 2013. "All 100 Senators Are Now on Twitter." The Verge. Available at www. theverge.com/2013/1/20/3896648/twitter-usage-among-members-of-us-congress.

Tumasjan, Andranik, Timm O. Sprenger, Phillip G. Sandner, and Isabell M. Welpe. 2011. "Election Forecasts with Twitter: How 140 Characters Reflect the Political Landscape." Social Science Computer Review 29 (4): 402-18. 